\title{
Dynamic Mechanical and Chemorheology Analysis for the Blended Epoxy System with Polyurethane Modified Resin
}

\author{
Xue Xin ${ }^{1, \#}$, Yu Rong ${ }^{1, \#}$, Linping $\mathrm{Su}^{1}$, Zhengmei Qiu ${ }^{1}$, Chenjun Yang ${ }^{1}$, Ming Liang ${ }^{1, *}$, Ping Ji $^{2}$, \\ Guoqiang Zhong ${ }^{3}$ and Zhanyong Yao ${ }^{1, *}$ \\ ${ }^{1}$ School of Qilu Transportation, Shandong University, Jinan, 250002, China \\ ${ }^{2}$ Shandong Hi-Speed Group Co., Ltd., Jinan, 250014, China \\ ${ }^{3}$ Shandong Provincial Communications Planning and Design Institute Group Co., Ltd., Jinan, 250031, China \\ *Corresponding Authors: Ming Liang. Email: ming.liang@sdu.edu.cn; Zhanyong Yao. Email: zhanyong-y@chd.edu.cn \\ "Xue Xin and Yu Rong contributed equally to this manuscript \\ Received: 23 June 2021 Accepted: 17 August 2021
}

\begin{abstract}
As the important matrix material, epoxy resin has been widely used in the composites for various fields. On account of the poor toughness of epoxy resin limiting their suitability for advanced applications, considerable interests have been conducted to modify the epoxy resin to meet the engineering requirements. In this study, the bio-based polyurethane (PU) modified resin was adopted to modify the pure bisphenol-A epoxy by blending method with various proportions. Aiming to illuminate the curing behavior, mechanical and thermal properties, the blended epoxy systems were characterized by viscosity-time analysis, dynamic mechanical analysis (DMA) at different frequencies and temperatures, mechanical tensile test, thermogravimetric analysis (TGA) and Fourier transform infrared (FT-IR) spectroscopy. The results indicated that the introduction of PU modified epoxy was found to significantly inhibit the viscosity growth rates especially when the content of PU modified epoxy resin is higher than $60 \%$. Notwithstanding the dynamic modulus and $\mathrm{T}_{\mathrm{g}}$ reduced with the increment of PU modified epoxy, remarkable increment on the elongation at break was found and the flexibility was greatly promoted with the introduction of PU modified epoxy. The proportion of PU modified epoxy in the blends should be put balance considerations to obtain optimal mechanical properties. TGA results and FTIR spectrum demonstrated that the addition of PU modified epoxy did not change the thermal decomposition mechanism and chemical reaction mechanism, but the addition of PU modified epoxy inhibits the curing reaction of epoxy resin by measured and calculated the damping temperature domain $\Delta \mathrm{T}$ from $35.7^{\circ} \mathrm{C}$ to $48.9^{\circ} \mathrm{C}$.
\end{abstract}

\section{KEYWORDS}

Dynamic mechanical property; chemorheology analysis; blended epoxy system; polyurethane modified resin

\section{Introduction}

Composite materials are prepared by physical, chemical or other blending methods composing of at least two materials with different specialties [1,2]. With the comprehensive performance improved by synergistic effect and complement each other by various materials, composite materials have become one of the most important materials for engineering application [3,4]. Among which, the polymer or carbon materials 
reinforced epoxy resin composite materials are widely used in aviation, aerospace, transport engineering, wind power, rail transportation and automobile manufacturing, etc., with the properties of good strength, stiffness, damping, corrosion resistance, and electrical conductivity [5,6]. Furthermore, the epoxy resin composite materials can realize the integration of design, structure and manufacture so as to reduce the whole life cycle cost. However, the composite's performance has some distinctions to meet different requirements for various applications. In previous studies, two main aspects have been focused on regulating the performances of composites by researchers. One is choosing the additives with different structures or types, for example, CNTs [7,8], graphene [9,10], carbon fiber [11], etc. Besides, the type, strength, heat resistance and electromagnetic shielding properties of epoxy resin matrix also have great influence on the properties of composites [12,13]. Composites with different preparation and molding processes have diverse requirements on the viscosity and curing dynamic process of matrix resin. Furthermore, due to the high crosslinking density, the cured epoxy resin is not only brittle, but also prone to crack with poor fatigue resistance. The poor toughness of epoxy resin has been a bottleneck for the advanced applications, so considerable interests have been conducted to modify epoxy resin recently [14-17].

Over the past years, remarkable achievements have been got in the research of toughness improvement for epoxy resin. In principle, there are mainly four ways to realize this target. Firstly, specific materials with elastic chain, such as the rubber elastomer and thermoplastic resin, are added into the epoxy resin during curing process $[14,18]$. Secondly, dispersed phases such as rigid particles, liquid crystal polymers, coreshell polymers and inorganic nanomaterials are added to the epoxy resin matrix to increase toughness [19-21]. Thirdly, curing agents with "flexible chain segment" in the molecular chain are rationally applied to introduce some flexible chain segment into the crosslinking network [22]. Thus, some thermosetting resins are penetrated into the epoxy resin network to form interpenetrating and semipenetrating network structure [23]. These interesting works have proved the advantages of toughness improvement for epoxy. However, the research on toughening and modification of epoxy resin is still not complete. Very few studies have been carried out to systematically study the dynamic mechanical properties, mechanical tensile properties and thermodynamic properties of modified epoxy resin. Therefore, it is still of great significance to carry out the research to obtain the epoxy resin matrix material with better comprehensive performance.

Interpenetrating polymer networks (IPNs) are composed of two or more than two networking polymer through each other and tangling form of polymer blend. In the IPNs, one material is randomly perforative into another kind of material, which leads to be forced mutual capacitance and the role of "synergistic effect". IPNs have attracted much attention because of the synergistic effect on improving material properties. In general, polymer modification results in an average of the properties of two materials, that is to say, to improve one of the properties of the material, the other properties of the material will be reduced. For example, the heat resistance and toughness of epoxy resin are difficult to be improved by general methods due to mutual restriction. However, the synergistic effect of IPNs can make the impact strength, modulus, elongation at break, hardness and heat resistance of the polymer higher than each component at the same time.

Containing flexible macro-molecule polymer chain segment in the molecular structure, the polyurethane (PU) can serve as plastic and rubber for both [24]. PU has excellent characteristics of high tensile strength and elongation at break. Furthermore, PU has good compatibility with epoxy resin and can be connected with epoxy resin in the form of covalent bond [25]. In the current study, the polyurethane modified epoxy resin was introduced into the bisphenol-A epoxy resin system in varying proportions for toughness and flexibility balance. The viscosity-time properties, dynamic mechanical analysis (DMA), mechanical tensile properties of modified epoxy resin system were measured. Thermo-gravimetric analysis (TGA) was used to study the curing reaction process of the epoxy resin system. Furthermore, comparisons of the characteristic absorption 
peak before and after modification were studied by Fourier transform infrared (FT-IR) spectroscopy to analyze the reaction mechanism.

\section{Experimental Section}

\subsection{Materials}

The thermosetting epoxy resin compounded by bisphenol A and epichlorohydrin was available by commercially. With the epoxide number of $0.48-0.54 \mathrm{eq} / 100 \mathrm{~g}$, organic chloride $\leq 0.02 \mathrm{eq} / 100 \mathrm{~g}$, inorganic chloride $\leq 0.001 \mathrm{eq} / 100 \mathrm{~g}$, viscosity at $25^{\circ} \mathrm{C}$ of $12000 \mathrm{mPa} \cdot \mathrm{s}$, the epoxy resin is colorless, transparent and presents viscous liquid condition at room temperature. The PU modified epoxy resin was purchased from Zhuzhou Polymer Co., Ltd., China. For the raw materials, the PU modified epoxy rein is a bio-based resin. In the processing of the PU modified epoxy, the dimer acids react with the hexanediol to form dimeric acid polyester diolhexanediol and then which is introduced of the polyurethane. As a natural renewable resource, the dimer acids are completely converted from biomass. According to the material supplier, the PU modified epoxy resin (yellowish transparency, epoxide number is 0.41$0.47 \mathrm{eq} / 100 \mathrm{~g}$, viscosity at $25^{\circ} \mathrm{C}$ is $1300 \mathrm{mPa} \cdot \mathrm{s}$ ) can form the IPN structure or semi interpenetrating polymer network (semi-IPN) combining with high elasticity of polyurethane and well heat resistance of epoxy resin. The curing agent was polyamide, which was prepared by the reaction of linoleic acid dimer and aliphatic polyamine. The chemical structure schematic of epoxy resin and PU modified epoxy resin are showed in Fig. 1.

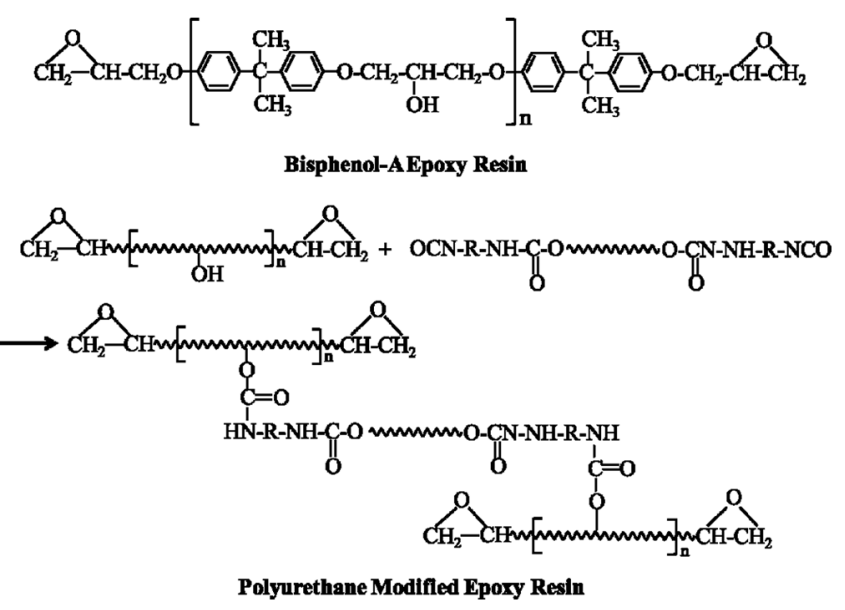

Figure 1: Chemical structure schematic of bisphenol-A epoxy resin and PU modified epoxy resin

\subsection{Sample Preparation}

The pre-vacuumized and defoamed bisphenol-A epoxy resin was poured onto the side of a tilted plastic cup. Then the PU modified epoxy resin was added with percent of $0,20,40,60,80$ and $100 \mathrm{wt} \%$. The blending ratios and the specimen codes were shown in Table 1 . The physical blending systems were stirred vigorously by a mechanical mixer at $600 \mathrm{rpm}$ for $10 \mathrm{~min}$ at room temperature. Whereafter, curing agent was subjected to the above systems at a stirred state and stirred for a further 15 min to get the better homogeneity. Afterwards, the mixture blends were poured into the teflon moulds with different size and shape for conducting various measurements. Later, the specimens were cured for $24 \mathrm{~h}$ at room temperature firstly and then at elevated temperature of $80^{\circ} \mathrm{C}$ for $2 \mathrm{~h}$. After the curing, samples were cooled naturally to room temperature and demolded for characterization measurements. 
Table 1: The blending ratios and the specimen codes of various samples

\begin{tabular}{llll}
\hline Sample number & Bisphenol-A epoxy resin/wt.\% & PU modified epoxy resin/wt.\% & Curing agent/wt.\% \\
\hline T01 & 100 & 0 & 40 \\
T02 & 80 & 20 & 40 \\
T03 & 60 & 40 & 40 \\
T04 & 40 & 60 & 40 \\
T05 & 20 & 80 & 40 \\
T06 & 0 & 100 & 40 \\
\hline
\end{tabular}

\subsection{Characterization Measurements}

Viscosity-time property

The viscosity-time characteristics of the blended epoxy resins were evaluated by rotational viscosity with the rotational speed of $100 \mathrm{rpm}$ using Brookfield viscometer. The viscosity-time characteristic was performed for preliminary verification of the curing development tendency at the initial stage after casting. Same test conditions were employed for all samples in order to assure repeatable results, including preheating time, preshearing time, rotator and torque range.

Dynamic mechanical analysis (DMA)

Dynamic mechanical tests were performed by a Discovery DMA 850 TA Instruments using the three points bending configuration with the span of $20 \mathrm{~mm}$. The $25 \mathrm{~mm} \times 5 \mathrm{~mm} \times 2 \mathrm{~mm}$ dimension samples were investigated at two different scan programs, frequency sweep and temperature ramp. In the frequency sweep mode, samples were subjected from 0.1 to $100 \mathrm{~Hz}$ at constant temperature of $25^{\circ} \mathrm{C}$ with the controlled strain of $1 \%$. In the temperature ramp mode, samples were subjected from room temperature to $200^{\circ} \mathrm{C}$ with a heating ramp of $2{ }^{\circ} \mathrm{C} / \mathrm{min}$ at the constant frequency of $10 \mathrm{~Hz}$ [26].

\section{Mechanical tensile analysis}

Mechanical tensile properties were tested to investigate the strength, elasticity modulus and elongation at break of blended epoxy resins through the tensile measurement and strain-stress test. The dumbbell-shaped samples were tested using a SANS UTM4000 universal test machine with a constant elongation rate of $2 \mathrm{~mm} / \mathrm{min}$. The results reported in this paper were averaged over the tested three samples.

\section{Thermal analysis}

The thermal properties were tested by the TGA on Mettler Toledo TGA SDTA851, Switzerland. The cured products were ground into powders and weighted for about $5 \mathrm{mg}$ to put into the sample plate. Samples were heated at a rate of $10^{\circ} \mathrm{C} / \mathrm{min}$ from 40 to $600^{\circ} \mathrm{C}$ in a dry nitrogen atmosphere with a $50 \mathrm{~mL} / \mathrm{min}$ flow rate.

Fourier transforms infrared (FTIR) spectroscopy

FTIR spectroscopy is an effective technique to identify the chemical structure of materials. In the test, the cured sample films were manually mixed with potassium bromide $(\mathrm{KBr})$ and palates were formed by pressing and immediately placed into the FT-IR instrument (Thermo Fisher's Nicolet 380, esolution is $4 \mathrm{~cm}^{-1}$ and scan rate is 32 times/s). The prepared specimens were scanned by FT-IR spectrometer and the infrared spectra were recorded within the range of wave number from 4,000 to $400 \mathrm{~cm}^{-1}$.

\section{Results and Discussions}

\subsection{Viscosity-Time Property}

For different application fields, the reaction rates of matrix epoxy resin are expected to be adjustable [27]. For example, the matrix epoxy resin should show lower reaction rate relatively and have a certainly 
operational time to prevent implosion at room temperatures in the area of composites manufacturing. Whereas, epoxy resin is expected to be cured rapidly when is using as adhesive, sealant or stuffing material. Thus, the relationship of viscosity with time of epoxy resin is a key technical parameter to evaluate the material characteristics. In this paper, the correlation between viscosity and time characteristics of the resulting epoxy resin were tested at $80^{\circ} \mathrm{C}$ with the detection duration of $480 \mathrm{~s}$ after initial preparation, which is performed to track the curing reaction and deduce the operable time for the practical application. Results of viscosity increment with curing time after blending with PU modified epoxy resin are showed in Fig. 2.

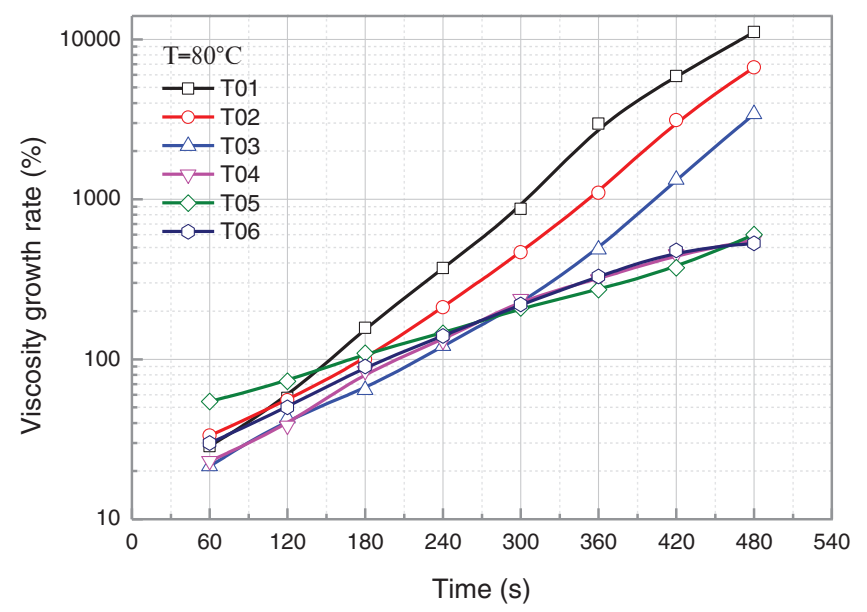

Figure 2: Viscosity-time characteristic for the blended epoxy resin

As shown in Fig. 2, viscosity of all samples present the trends of similarly exponential growth with time. In other words, the viscosity increases rapidly after the preparation of blended epoxy resin, since the chemical crosslinking starts to take place. However, the viscosity growth rates (the slope of curves) present a large variation for different samples. Sample of T01 without any PU modified epoxy resin shows the fastest growth rate of viscosity, which means the cross-linking and reaction rate between bisphenol-A epoxy resin and curing agent is higher than which between PU modified epoxy resin and curing agent apparently. Samples of T02 and T03 with a certain addition of PU modified epoxy resin show similar tendencies but lower growth rate compared to T01. However, when the contents of PU modified epoxy resin are higher than $60 \%$ (for T04-T06), the blended epoxy systems present significantly lower viscosity growth rate than the systems with dominant bisphenol-A epoxy resin, which shows the similar conclusion with reference $[28,29]$. The polyurethane can prevent curing of epoxy resin, which is mainly attributed to the slower reaction with the curing agent. Because of containing the flexible macromolecule polymer chain segment in the molecular structure and branched chain structure, the contact area between the epoxy ring and the curing agent will be reduced.

\subsection{Dynamic Mechanical Analysis}

Dynamic mechanical analysis is an effective method for evaluating the structural change-molecular motion-properties of polymer material. In the DMA tests, variation of dynamic mechanical properties of polymer with temperature, time and frequency can be obtained so as to evaluate the heat resistance, cold resistance, compatibility, damping efficiency and processing performance for polymer materials [30]. It is well known that the glass-transition, crystallization, orientation, crosslinking and phase separation of polymers are closely related to the changes of molecular motion. The advantage of all the above mentioned characteristics can be sensitively reflected in the dynamic mechanical properties, so 
considerable interests have been put on the DMA by researchers in the field of polymer material science and engineering. Typical parameters including the complex modulus $\mathrm{E}^{*}$, storage modulus $\mathrm{E}^{\prime}$, loss modulus $\mathrm{E}^{\prime \prime}$ and loss factor $\tan \delta$ can be presented with the variation of temperature and frequency, in which $\mathrm{E}^{\prime}$ represents the elastic feature and rigidity of material, $E^{\prime \prime}$ represents the viscous feature and is in proportion to the consumption energy in the form of heat. The loss factor $\tan \delta$ is calculated by the ratio of $E^{\prime \prime}$ and $E^{\prime}$, which represents the damping capacity of material. The frequency sweep and temperature ramp were carried out for samples during DMA tests and the results were deeply analyzed to evaluate the influence of PU modified epoxy.

\subsubsection{Frequency Sweep}

Frequency sweep is performed to study the relationship between the viscoelasticity and frequency under fixed temperature and strain. It is usually used to detect structures and to observe longtime and shorttime performance. Time-temperature superpositions were carried out in the study. The frequency sweeps at $25^{\circ} \mathrm{C}$ and $50^{\circ} \mathrm{C}$ were conducted. Master curves at the reference temperature $25^{\circ} \mathrm{C}$ of were obtained based on time-temperature superposition principle. Moreover, the deep discussions on frequency dependence of elastic modulus, loss modulus and phase angle were also incorporated in wide frequency range. Master curves of various epoxy resin samples are displayed in Fig. 3. As can be seen, storage modulus $\mathrm{E}^{\prime}$ (Fig. 3a), loss modulus E" (Fig. 3b) and loss factor tan $\delta$ (Fig. 3c) present the completely different trends with the frequency increase from 0.01 to $100 \mathrm{~Hz}$.

In Fig. 3a, E' of all the blended epoxy resin increase with the frequency. However, two distinct behaviors can be found depending on the PU modified epoxy content. For the low PU modified epoxy contents (T02 and T03), the frequency spectra have not deviated too much from the pure bisphenol-A epoxy resin (T01) and the difference value become narrow as frequency increases. $\mathrm{E}^{\prime}$ appear roughly approximate each other but significantly lower than T01 especially at low frequencies for samples with high PU modified epoxy contents (T04 and T05), indicating significant changes in the system. Besides, the slope of $E^{\prime}$-frequency curves just present slight increase with the addition of PU modified epoxy. Nevertheless, for the pure PU modified epoxy (T06), $\mathrm{E}^{\prime}$ decreases drastically and attains the increment for more than one order of magnitude when frequency changes. Additionally, the slope of $E^{\prime}$-frequency curve increases sharply. Comparing to the storage modulus $\mathrm{E}^{\prime}$ of $\mathrm{T} 01$ and T06, the former is 150 times higher than the latter at low frequency and 15 times at high frequency, which indicates that the elastic component of T06 at high frequencies is higher than that at low frequencies.

In Fig. 3b, loss modulus E" of T01 and T02 show a completely different trend with other samples, that is $E^{\prime \prime}$ decrease with the increase of frequency. Nevertheless, as found for the E"-f curves for T03-T06, the similar behaviors can be distinguished as to E'-f curves. In the context of T03, the highest absolute $E^{\prime \prime}$ value of all the samples appeared at low frequency and the increment of E"-f curve slope is very slow even almost level off. Decrease in E" together with a higher slope of E"-f curves for T04 and T05 can be observed. Thus, T06 emerges a significant decrease with about 30 times smaller than T03 at low frequency. Additionally, the slope of the $E^{\prime \prime}-f$ curve increases sharply. Loss modulus $E^{\prime \prime}$ is always smaller than storage modulus $\mathrm{E}^{\prime}$ in the tested frequency region at $25^{\circ} \mathrm{C}$, which indicates that the bulk rheological behavior is dominated by viscous properties. By comparing the discrepancy between $\mathrm{E}^{\prime}$ and $\mathrm{E}^{\prime \prime}$ of the six samples, it's no hard to find that the discrepancy dwindle gradually as the addition of PU modified epoxy. It seems that $E^{\prime \prime}$ would be nearly equal to $E^{\prime}$ for sample T06, indicating the elastic component and viscous component is approximately similar. These phenomena can further verify the above-mentioned viewpoints.

Fig. 3c depicts the loss factor tan $\delta$ as a function of frequency spectra for the blended epoxy resin. It is regarded that the viscoelastic property of material can be analyzed by the magnitude of phase angle $\delta, \delta=0^{\circ}$ means an ideal elastic material, $\delta=90^{\circ}$ means an ideal viscous material. Phase angle $\delta$ for material is 
generally between $0^{\circ}$ and $90^{\circ}$. As presented in Fig. 4c, epoxy resins with different PU modified epoxy caused different energy loss properties. Throughout all samples, the loss factor increase with the PU modified epoxy content, indicating the increasing viscous component in the system from T01-T06. For T01-T05, monotonic decrease of loss factor with frequency is observed, despite the decline magnitude are various. The energy loss factor is lower at high frequency state than that at low frequency state, signifying the epoxy system is more likely to behave as viscous feature at low frequency. For T06, the loss factor presents visible increment than other samples even close to 1.0, which means the PU modified epoxy appears to be viscous material more likely and tends to present high energy loss and endogenous heat. Notably, a hump is observed in the curve of T06, indicating the loss factor approaches the peak value at $0.3-0.4 \mathrm{~Hz}$.

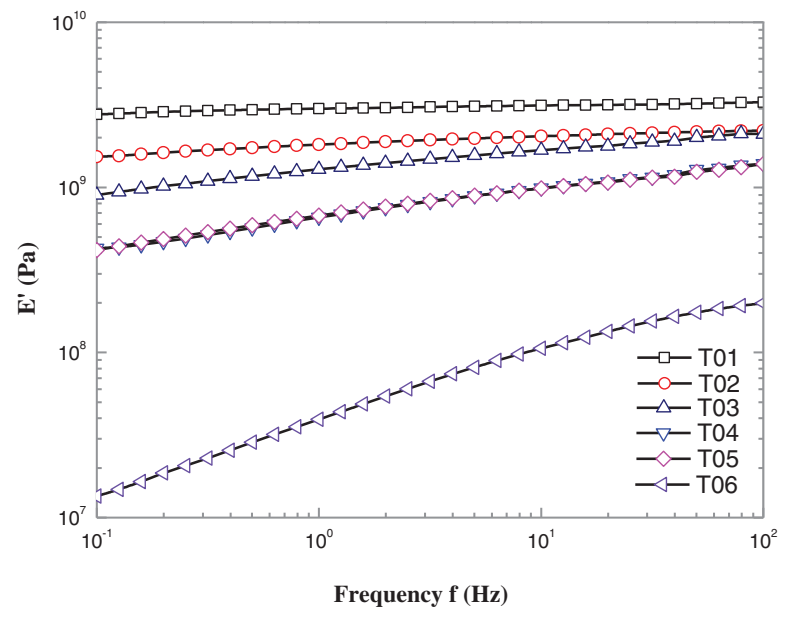

(a)

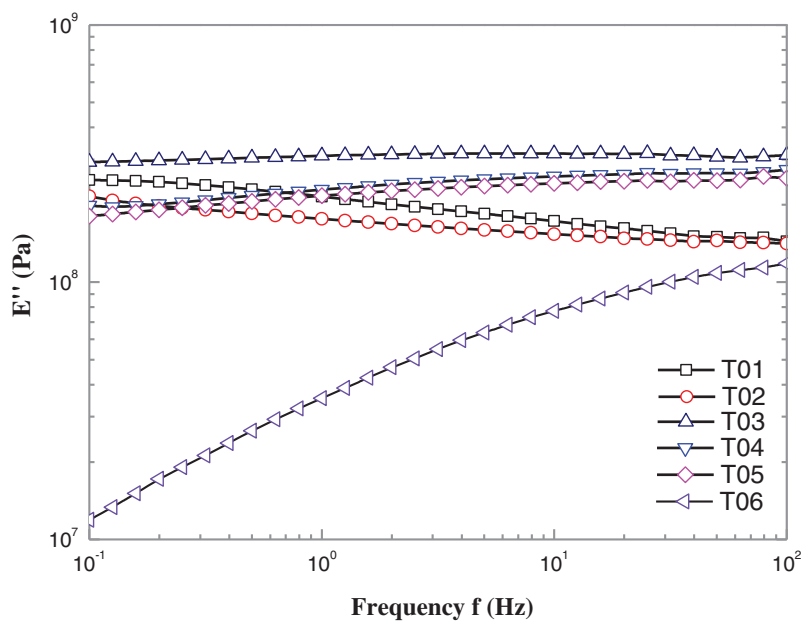

(b)

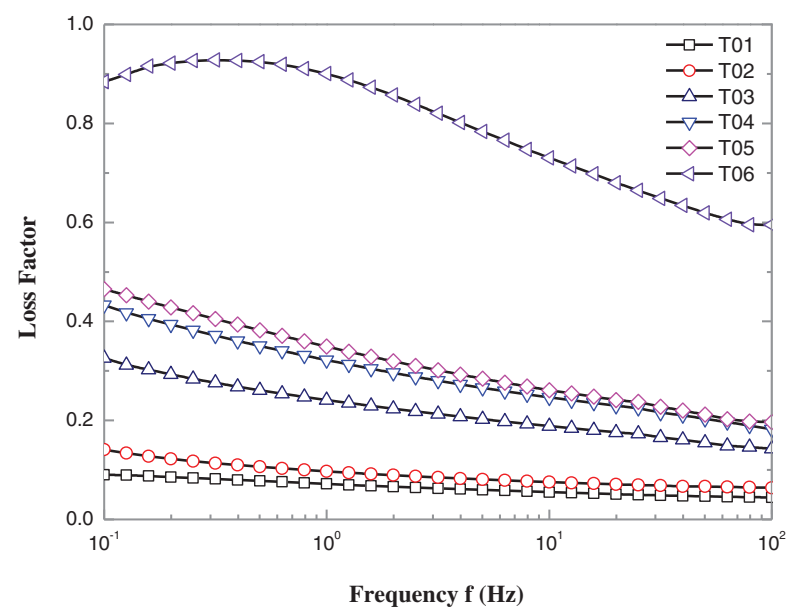

(c)

Figure 3: Dynamic rheological parameters as a function of frequency for the blended epoxy resin. (a) storage modulus $\mathrm{E}^{\prime}$, (b) loss modulus $\mathrm{E}^{\prime \prime}$, (c) loss factor tan $\delta$ 


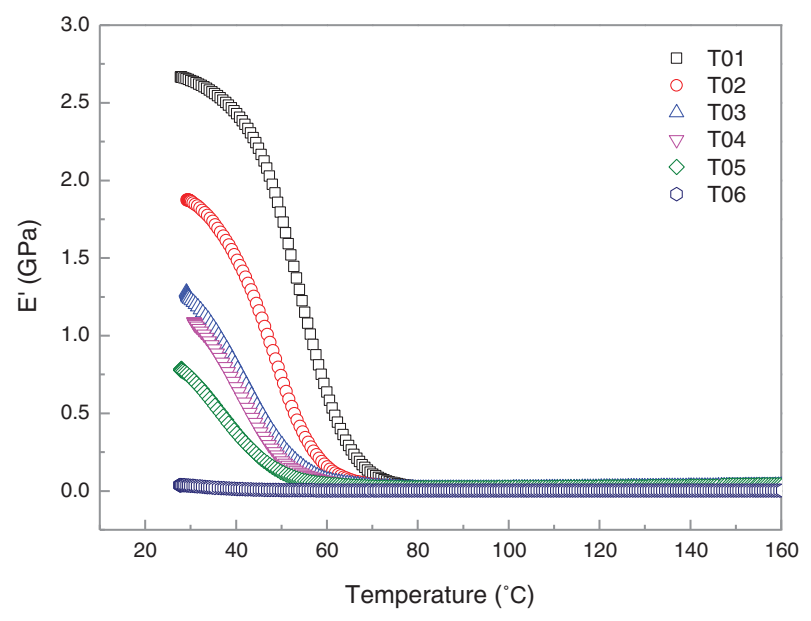

(a)

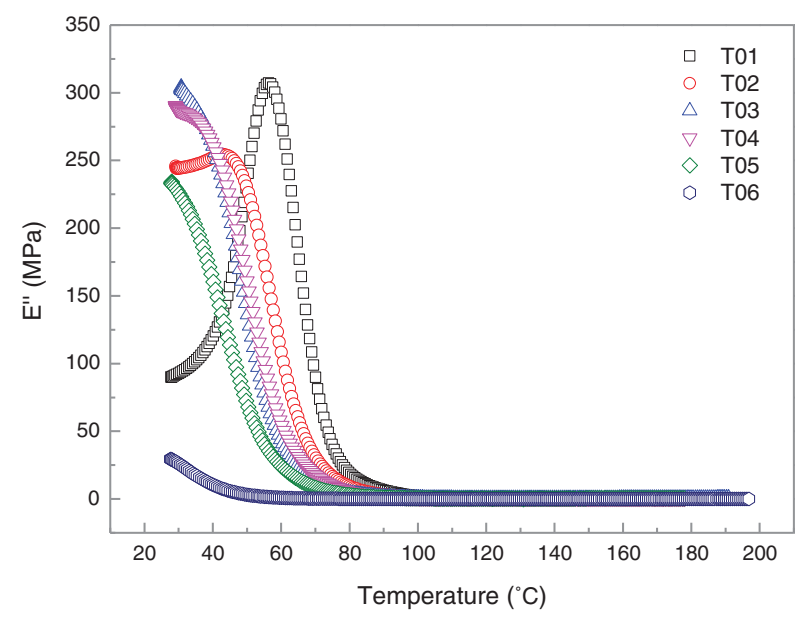

(b)

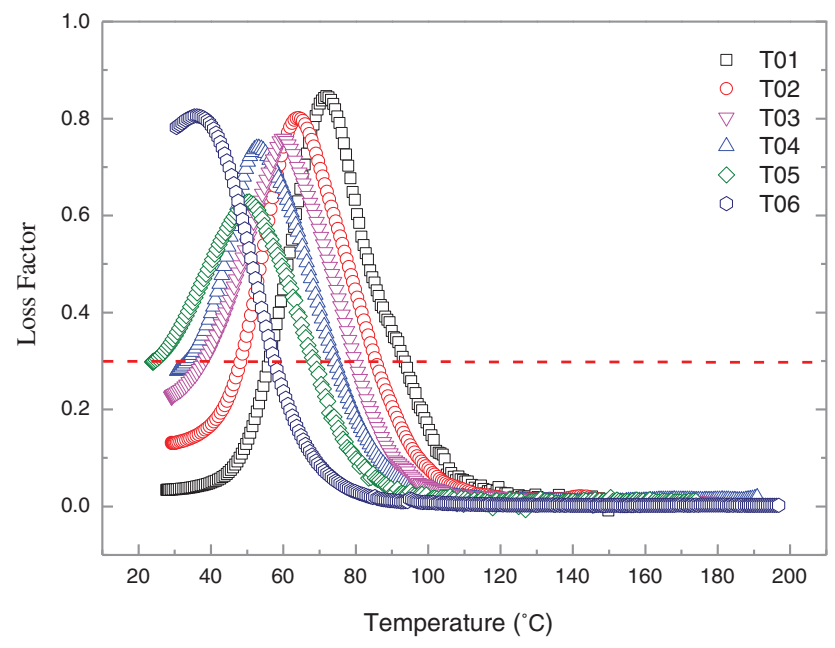

(c)

Figure 4: Dynamic rheological data as a function of temperature for the blended epoxy resin. (a) storage modulus $\mathrm{E}^{\prime}$, (b) loss modulus E", (c) loss factor tan $\delta$

\subsubsection{Temperature Ramp}

In the DMA tests, temperature ramp test can evaluate the relationship between viscoelastic energy and temperature of materials [31]. Effects of PU modified epoxy on dynamic rheological behavior were also evaluated by temperature sweeps. Temperature dependence of storage modulus E', loss modulus E" and loss factor $\tan \delta$ for various PU modified epoxy content are depicted in Fig. 4, in which the temperatures range is from 25 to $200^{\circ} \mathrm{C}$. It is observed that temperature generates an obvious effect on the modulus. With the increase of temperature, the free volume of pure bisphenol-A epoxy resin and PU modified epoxy resin increases gradually and the motion ability of molecular chain segment is enhanced continuously, which leads to the weakened resistance to external forces. Therefore, the storage modulus $\mathrm{E}^{\prime}$ of both pure epoxy resin and PU modified epoxy resin decreases gradually, see Fig. 4a. All the samples of $\mathrm{E}^{\prime}$ show the tendency of falling rapidly to a certain approximate value as the temperature ramp. In comparison of pure bisphenol-A epoxy resin (T01), the lower storage modulus $\mathrm{E}^{\prime}$ is observed for blended system with more PU modified epoxy, which indicates a softer and more viscous component. 
This is attributed to the PU molecular structure containing flexible macromolecule chain segment. Meanwhile, the deviation among the six blended samples on $\mathrm{E}^{\prime}$ at low temperature is large. The decreasing trend of blends containing more PU modified epoxy is less distinct. On the other hand, loss modulus $\mathrm{E}^{\prime \prime}$ is always lower than the storage modulus $\mathrm{E}^{\prime}$, indicating the dominant elastic properties in the studied temperature ranges. This phenomenon becomes notable with an increase of percentage of PU modified epoxy. In other words, pure bisphenol-A epoxy resin is the most resistant to temperature variation. Comparing to the literature [32], the epoxy network containing different plasticizers displayed a slightly distinction of glass-transition temperature than the non-modified epoxy, which suggesting that the miscibility of the system is probably related to the strong interaction between the components.

According to the motion forms of molecular chain, three apparent states of polymer materials can be observed: glass state, rubber state and viscous flow state. When the polymer material is in the glassy state, the molecular chain segment is frozen-like, following the hooke deformation law when subjected to the external force. Rubber state is named because of the rubber-like high elastic behavior characterized by a large deformation under a small external force. During the transition process from glass state to rubber state, a crucial parameter: Glass transition temperature $\left(T_{g}\right)$ is investigated with considerable interest. As the amorphous polymer material, the strength, modulus and other mechanical properties of the blended epoxy resin system will change significantly near $\mathrm{T}_{\mathrm{g}}$. In the vitrification transition zone, the polymer diffuses in a short range with micro Brownian motion. The chain segment of epoxy moves freely from one quasi-lattice position to another position, further resulted in polymer becomes soft and rubbery. In dynamic mechanics, the loss modulus $\mathrm{E}^{\prime \prime}$ and loss factor tan $\delta$ will show maximum values, see Figs. $4 \mathrm{~b}$ and $4 \mathrm{c}$. From the height and width of glass transition peak, we can speculate the relaxation characteristics of the blended epoxy. The relaxation transformation of the chain segment is more difficult and requires a larger energy peak width at the situation of high peak height (see T01), which reflects the great dispersion of the chain segment movement. Furthermore, the temperature corresponding to the peak point in $\tan \delta$ temperature curves represents $\mathrm{T}_{\mathrm{g}}$, which is listed in Table 2 for all the blended epoxy systems. As displayed in Table 2, the values of $\mathrm{T}_{\mathrm{g}}$ are decreasing with the increment of PU modified epoxy content, demonstrating the lower service temperature and poor thermal transformation properties.

Table 2: Vitrification transition temperature $\mathrm{T}_{\mathrm{g}}$ and damping temperature domain $\Delta \mathrm{T}$ for blended epoxy systems

\begin{tabular}{lllllll}
\hline Samples & $\mathrm{T} 01$ & $\mathrm{~T} 02$ & $\mathrm{~T} 03$ & $\mathrm{~T} 04$ & $\mathrm{~T} 05$ & $\mathrm{~T} 06$ \\
\hline $\mathrm{T}_{\mathrm{g}}\left({ }^{\circ} \mathrm{C}\right)$ & 73.2 & 63.4 & 60.7 & 54.6 & 50.3 & 36.8 \\
$\Delta \mathrm{T}\left({ }^{\circ} \mathrm{C}\right)$ & 35.7 & 37.6 & 39.8 & 41.2 & 43.6 & 48.9 \\
\hline
\end{tabular}

In addition, the temperature region $\Delta \mathrm{T}$ for $\tan \delta>0.3$ obtained from the tan $\delta$-temperature curve can be generally used to evaluate the damping temperature domain of material. The damping temperature domains for blended epoxy systems are also demonstrated in Table 2. As can be seen from Table 2, the introduction of PU modified epoxy in blended epoxy system leads to a significant growth in damping temperature domain, which shows that blended epoxy system possesses the higher ability to convert mechanical vibration into heat energy or other energy that can be lost.

\subsection{Mechanical Tensile Property}

To identify whether the blended epoxy resin can be used for various fields, the mechanical properties should be assessed, including elasticity modulus, tensile strength and elongation at break [33]. Mechanical tensile test was performed to investigate these parameters by directly obtained or calculated from the stress-strain curve, see Fig. 5. As demonstrated, all the blended epoxy display similar 
stress-strain curve. At the initial period, the strain increases as the external stress by approximately linear growth. The blends are in the elastic deformation stage during this period with the peculiarity of recovering original condition, once the stress is removed. As expected, the pure bisphenol-A epoxy resin (T01) presents highest linear growth rate, demonstrating the strongest resistance to deformation. Growth rate showed the decreasing trend as the amount of PU modified epoxy increased in the blends. With the external stress further increasing, the stress-strain curve tends to reach the horizontal situation and the nonrecoverable or plastic deformation occurs. Later, all the blends showed the sharply decrease trend and fracture emerge in the specimens. The strain value at the point of fracture can be evaluated by the parameter of elongation at break, which can reflect the tensile fracture toughness and ductility of blends. The addition of PU modified epoxy in blends produce significant increment on the elongation at break. This can be mainly attributed to the soft segment in the PU structure. Through blending with PU modified epoxy, the semi-IPN or IPN can be formed, which can significantly improve the fracture toughness of blends.

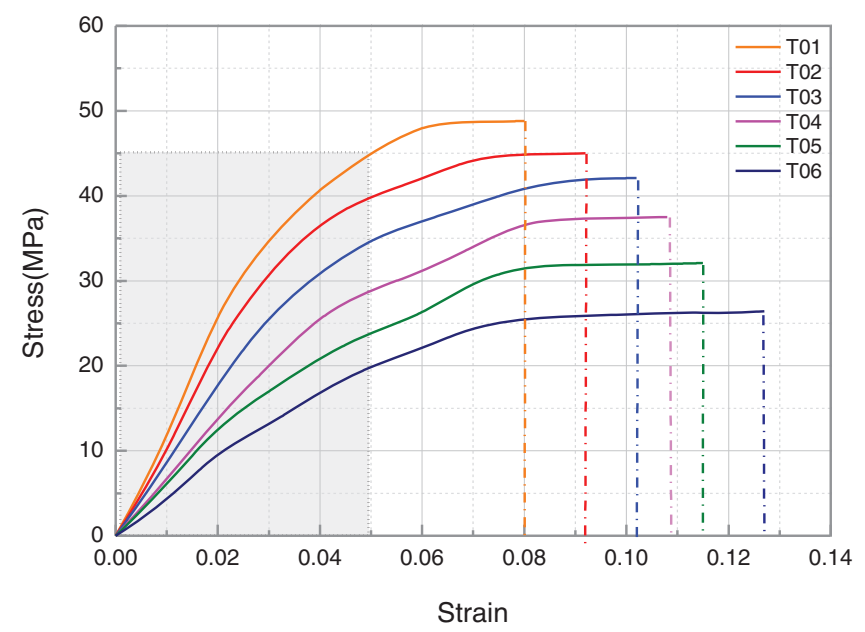

Figure 5: Stress-strain curve for the blended epoxy system

Furthermore, the corresponding elastic modulus and tensile strength were calculated by using the linear region marked in gray from the stress-strain curve and already illustrated in Fig. 6. Similar to the transformation law of the tensile strength and elongation at break with the increasing concentration of blender in literature [21], The elastic modulus and tensile strength of blends decreases on the addition of PU modified epoxy. The maximum elastic modulus and tensile strength reach to 1403 and $48.8 \mathrm{MPa}$ for T01. On the other hand, the minimum elastic modulus and tensile strength are 472 and $26.9 \mathrm{MPa}$ for T06, which are $66.3 \%$ and $44.9 \%$ lower than the neat epoxy, respectively. For other blends, the value of elastic modulus and tensile strength continue to diminish as the amount of PU modified epoxy rises.

Based on the above analysis, the proportion of PU modified epoxy in the blends should be considered in order to obtain optimal mechanical properties. If the focus is put on the well ductility, the ratio of PU modified epoxy should be enhanced. Nevertheless, increasing proportion of PU modified epoxy in the blends will weaken the performance of mechanical properties. Therefore, the equilibrium point between neat epoxy and PU modified epoxy should be considered.

\subsection{Thermal Stability Analysis}

The thermal stability and heat resistance are one of the main specialties for the blended epoxy resin. One of the most commonly used method to characterize the heat resistance and decomposition mechanism of materials is thermo gravimetric analysis (TGA), from which the thermal decomposition temperature can 
be obtained [34]. The TGA curves under a nitrogen atmosphere from 40 to $600^{\circ} \mathrm{C}$ for the blended epoxy systems are illustrated in Fig. 7. It is found that the neat epoxy, the PU modified epoxy and all the blended epoxy systems showed a single step of decomposition. The addition of PU modified epoxy did not change the general trend of TGA curve, indicating that the thermal decomposition mechanism was approximately same [33]. Furthermore, the neat epoxy (T01) showed best thermal stability with comparison of other blends, demonstrating the maximum serviceable temperature, in accordance with the research results in Section 3.2.2. In addition, the blends displayed slightly lower thermal stabilities values as compared to T01, due to the less well thermal stability of PU modified epoxy. DTG is the first-order differential of weight loss with respect to temperature or time, and represents the rate of weight loss. Generally, the peak value is the fastest rate of weight loss. Furthermore, the peak area of the DTG curve corresponds to the changed weight of sample. The thermal decomposition temperature can be characterized by the temperature value corresponding to the maximum mass loss rate. From Fig. 7b, we can see that, sample of T01 presents the lowest thermal decomposition temperature. After mixed with modified epoxy resin, the thermal decomposition temperature is improved, which can also fully verified the IPN interaction of the blend system.

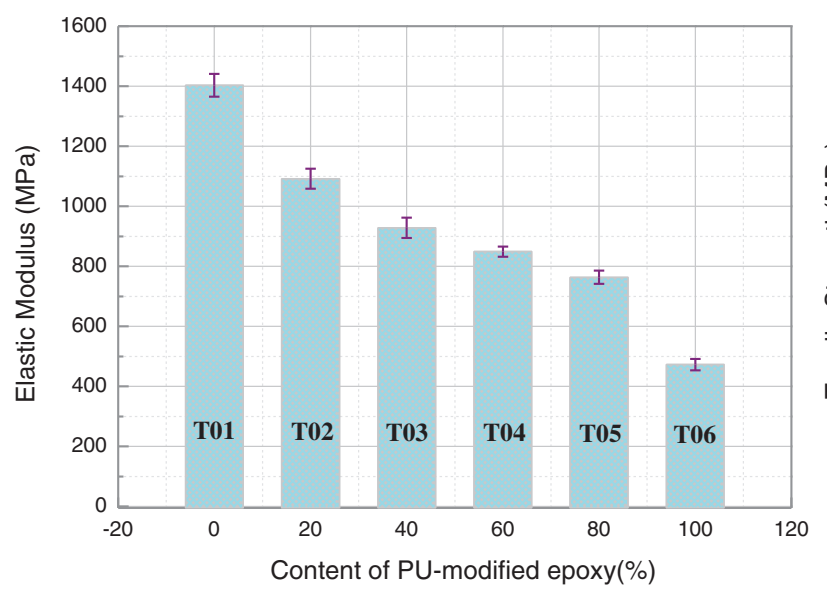

(a)

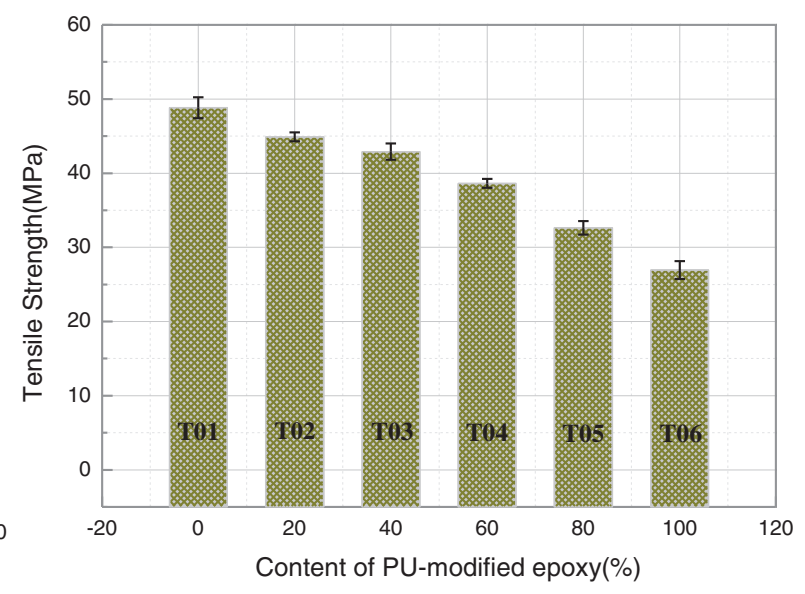

(b)

Figure 6: Elastic modulus and tensile strength for blends with various contents of PU-modified epoxy

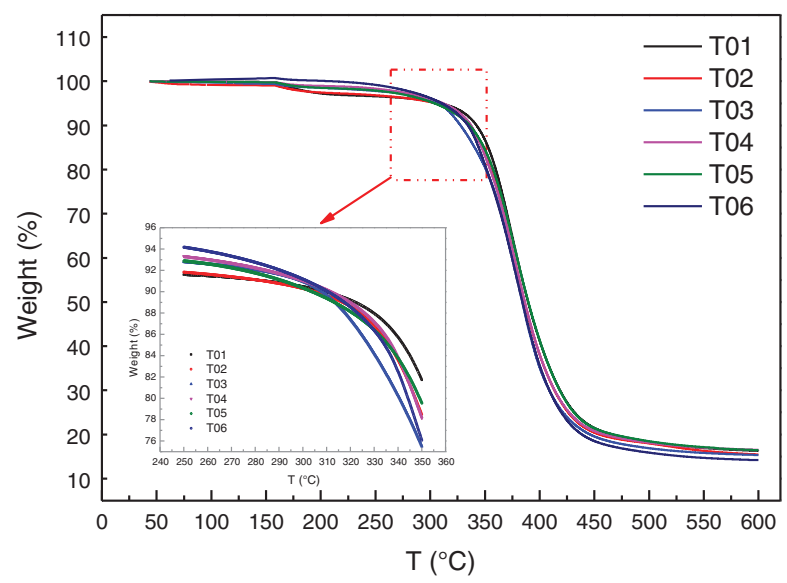

(a)

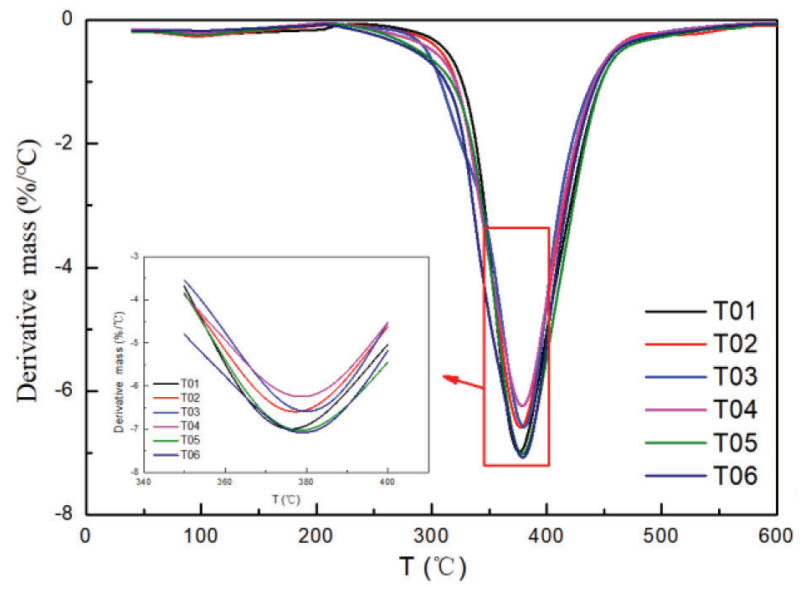

(b)

Figure 7: Thermo gravimetric curves for the blended epoxy, (a) TG curves, (b) DTG curves 
What is more, the corresponding thermal stability parameters were extracted from the TGA curves for quantitative evaluation on the thermal stability characteristic, depicted in Table 3.

$\mathrm{TS}=0.49\left[\mathrm{~T}_{5 \%}+0.6 \times\left(\mathrm{T}_{50 \%}-\mathrm{T}_{5 \%}\right)\right]$

$\mathrm{Td}=\left(10 \times \mathrm{T}_{15 \%}-3 \times \mathrm{T}_{30 \%}\right) / 7$

where $\mathrm{T}_{\mathrm{s}}$ means the temperature index. $\mathrm{T}_{5 \%}, \mathrm{~T}_{15 \%}, \mathrm{~T}_{30 \%}$ and $\mathrm{T}_{50 \%}$ represent the temperature value when weight loss is $5 \%, 15 \%, 30 \%$ and $50 \%$ respectively. It is regarded that the temperature index Ts is performed to characterize the long-term service temperature and apparent decomposition temperature of the material. Besides, the char yields at $600^{\circ} \mathrm{C}(\mathrm{Yc})$ were also listed in Table 3. It is easy to find that the apparent decomposition temperatures of the blends display little difference, which also confirms the decomposition mechanisms are not changed.

Table 3: Thermal stability parameters for blended epoxy system

\begin{tabular}{lllllll}
\hline Samples & $\mathrm{T} 01$ & $\mathrm{~T} 02$ & $\mathrm{~T} 03$ & $\mathrm{~T} 04$ & $\mathrm{~T} 05$ & $\mathrm{~T} 06$ \\
\hline $\mathrm{T}_{5 \%}\left({ }^{\circ} \mathrm{C}\right)$ & 309.5 & 304.8 & 308.0 & 311.8 & 303.7 & 310.6 \\
$\mathrm{~T}_{15 \%}\left({ }^{\circ} \mathrm{C}\right)$ & 353.0 & 347.4 & 340.5 & 347.0 & 349.1 & 344.2 \\
$\mathrm{~T}_{30 \%}\left({ }^{\circ} \mathrm{C}\right)$ & 370.2 & 367.2 & 365.0 & 367.0 & 369.3 & 364.3 \\
$\mathrm{~T}_{50 \%}\left({ }^{\circ} \mathrm{C}\right)$ & 389.5 & 386.2 & 384.2 & 386.3 & 389.6 & 384.2 \\
$\mathrm{~T}_{\mathrm{S}}$ & 175.2 & 173.3 & 173.3 & 174.7 & 174.1 & 173.8 \\
$\mathrm{~T}_{\mathrm{d}}$ & 345.6 & 338.9 & 330.0 & 338.4 & 340.4 & 335.6 \\
$\mathrm{Yc}$ at $600^{\circ} \mathrm{C}$ & 15.3 & 14.4 & 14.3 & 15.5 & 15.4 & 13.2 \\
\hline
\end{tabular}

\subsection{FTIR Characterizations}

Polymer molecular chain segment structure plays the decisive rule to the macroscopic properties such as mechanical and thermal property. In order to further study the reaction mechanism and to investigate the formation of crosslinking network structure, the FTIR spectroscopies [35,36] were depicted in Fig. 8 to detect the changes in the structure of curing products for neat epoxy (T01), blends with $40 \%$ PU modified epoxy (T03) and PU modified epoxy (T06). As shown in Fig. 8, we can found that the infrared characterization spectroscopy and functional groups of the curing system did not change significantly, except for the position and intensity of very few specific characteristic peaks. In the infrared spectrum, the characteristic absorption peaks at 3424.69 and $915 \mathrm{~cm}^{-1}$ represent the hydroxyl $(-\mathrm{OH})$ and epoxy group, respectively, and the characteristic absorption peaks of methyl $\left(-\mathrm{CH}_{3}\right)$ and methylene $\left(-\mathrm{CH}_{2}-\right)$ are at 2963.38 and $2870.28 \mathrm{~cm}^{-1}$, respectively. The characteristics bands located at $1458.59,1581.01$ and $1607.95 \mathrm{~cm}^{-1}$ correspond to bending vibrations of $\mathrm{C}=\mathrm{C}$ on the benzene ring. Furthermore, the antisymmetric contractile $\mathrm{C}-\mathrm{O}-\mathrm{C}$ of aliphatic aromatic ethers emerges at $1246.15 \mathrm{~cm}^{-1}$. The stretching vibrations and the peak located at $3034 \mathrm{~cm}^{-1}$ correspond to unsaturated $=\mathrm{C}-\mathrm{H}$ [33]. What is noteworthy is that the absorption peaks of three curing products at $915 \mathrm{~cm}^{-1}$ are almost completely disappeared, indicating that the epoxy groups in the resin were basically cured completely. Moreover, the stretching vibration peak of $\mathrm{C}=\mathrm{O}$ in carbonate $(-\mathrm{NHCOO}-)$ appeared at $1733.89 \mathrm{~cm}^{-1}$ for the PU modified epoxy, no appearing on the T01 spectrum, this suggests that there is a certain amount of polyurethane structure in T06. 


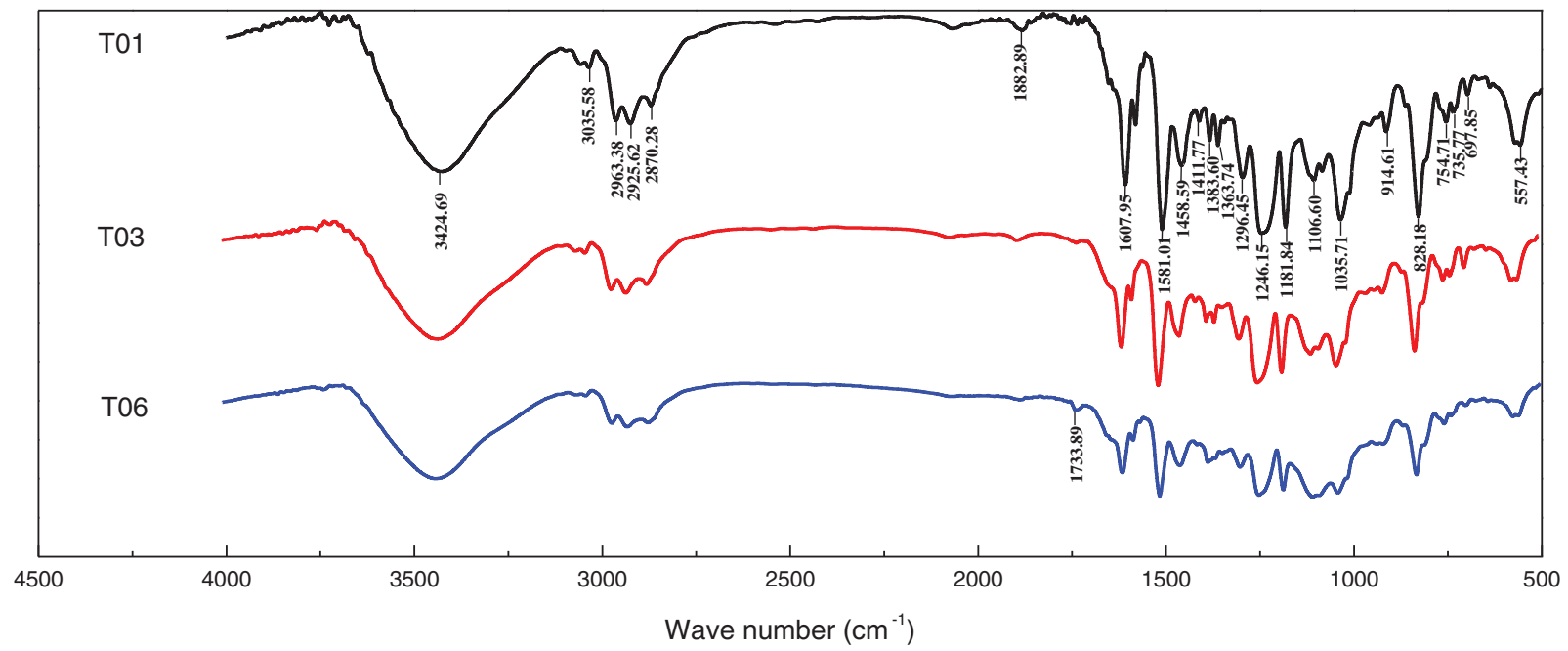

Figure 8: FTIR spectroscopy of neat epoxy (T01), blends with 40\% PU modified epoxy (T03) and PU modified epoxy (T06)

\section{Conclusion}

In this work, the effects of PU modified epoxy blended in the pure bisphenol-A epoxy resin and the properties for the blends were systematically studied. The influences of PU modified epoxy on viscositytime property, dynamic mechanical analysis, mechanical property, thermal stabilities and chemical structure of blends were evaluated. The main conclusions are summarized as following:

- Viscosity-time characteristic analysis indicated that the introduction of the PU modified epoxy has significant influence on the viscosity growth rates. The blended epoxy systems present significantly lower viscosity growth rate than the systems with dominant of bisphenol-A epoxy resin especially when the contents of PU modified epoxy resin are higher than $60 \%$.

- The dynamic mechanical property for the blends presented significant difference with the variation of frequency sweep and temperature ramp. The dynamic modulus is weakened and $\mathrm{T}_{\mathrm{g}}$ is decreased with the increment of PU modified epoxy content.

- In spite of the reduced resistance to deformation, the addition of PU modified epoxy in blends leads to significant increment on the elongation at break, which is attributed by the soft segment in the PU structure. The proportion of PU modified epoxy in the blends should be balanced in order to obtain optimal mechanical properties.

- From the perspective of TGA results and FTIR spectrum, the thermal decomposition trends and the infrared characterization spectroscopy and functional groups of the curing system did not change significantly, indicating the addition of PU modified epoxy did not change the thermal decomposition mechanism and chemical reaction mechanism, but the addition of PU modified epoxy inhibits the curing reaction of epoxy resin by measured and calculated the damping temperature domain $\Delta \mathrm{T}$ from $35.7^{\circ} \mathrm{C}$ to $48.9^{\circ} \mathrm{C}$.

Funding Statement: The authors acknowledge the financial support of the National Natural Science Foundation of China (No. 51908330), the Qilu Young Scholars Program of Shandong University, Natural Science Foundation of Shandong Province (CN) (No. ZR2020ME244), the Fundamental Research Funds of Shandong University (No. 2020GN059), the Fundamental Research Funds for the Central Universities, CHD (No. 300102210502) and Scientific Research Project of Shandong High-speed Group Co., Ltd., (No. SDGS-KJCX-2020-006-08). 
Conflicts of Interest: The authors declare that they have no conflicts of interest to report regarding the present study.

\section{References}

1. Pathak, A. K., Borah, M., Gupta, A., Yokozeki, T., Dhakate, S. R. (2016). Improved mechanical properties of carbon fiber/graphene oxide-epoxy hybrid composites. Composites Science and Technology, 135, 28-38. DOI 10.1016/j.compscitech.2016.09.007.

2. Pickering, K. L., Efendy, M. A., Le, T. M. (2016). A review of recent developments in natural fibre composites and their mechanical performance. Composites Part A: Applied Science and Manufacturing, 83, 98-112. DOI 10.1016/ j.compositesa.2015.08.038.

3. Chen, H., Ginzburg, V. V., Yang, J., Yang, Y., Liu, W. et al. (2016). Thermal conductivity of polymer-based composites: Fundamentals and applications. Progress in Polymer Science, 59, 41-85. DOI 10.1016/j. progpolymsci.2016.03.001.

4. Li, G., Sun, J., Hou, W., Jiang, S., Huang, Y. et al. (2016). Three-dimensional porous carbon composites containing high sulfur nanoparticle content for high-performance lithium-sulfur batteries. Nature Communications, 7(1), 110. DOI 10.1038/ncomms10601.

5. Azeez, A. A., Rhee, K. Y., Park, S. J., Hui, D. (2013). Epoxy clay nanocomposites-processing, properties and applications: A review. Composites Part B: Engineering, 45(1), 308-320. DOI 10.1016/j.compositesb.2012.04.012.

6. Wan, Y. J., Yang, W. H., Yu, S. H., Sun, R., Wong, C. P. et al. (2016). Covalent polymer functionalization of graphene for improved dielectric properties and thermal stability of epoxy composites. Composites Science and Technology, 122, 27-35. DOI 10.1016/j.compscitech.2015.11.005.

7. Chen, Y., Zhang, H. B., Yang, Y., Wang, M., Cao, A. et al. (2016). High-performance epoxy nanocomposites reinforced with three-dimensional carbon nanotube sponge for electromagnetic interference. Advanced Functional Materials.

8. Moghadam, A. D., Omrani, E., Menezes, P. L., Rohatgi, P. K. (2015). Mechanical and tribological properties of self-lubricating metal matrix nanocomposites reinforced by carbon nanotubes (CNTs) and graphene-A review. Composites Part B: Engineering, 77, 402-420. DOI 10.1016/j.compositesb.2015.03.014.

9. Wang, C., Zhao, M., Li, J., Yu, J., Sun, S. et al. (2017). Silver nanoparticles/graphene oxide decorated carbon fiber synergistic reinforcement in epoxy-based composites. Polymer, 131, 263-271. DOI 10.1016/j.polymer.2017.10.049.

10. Atif, R., Shyha, I., Inam, F. (2016). Mechanical, thermal, and electrical properties of graphene-epoxy nanocomposites-A review. Polymers, 8(8), 281. DOI 10.3390/polym8080281.

11. Ma, L., Zhu, Y., Wang, M., Yang, X., Song, G. et al. (2019). Enhancing interfacial strength of epoxy resin composites via evolving hyperbranched amino-terminated POSS on carbon fiber surface. Composites, 170, 148-156. DOI 10.1016/j.compscitech.2018.12.001.

12. Liu, F., Deng, S., Zhang, J. (2017). Mechanical properties of epoxy and its carbon fiber composites modified by nanoparticles. Journal of Nanomaterials, 1-9. DOI 10.1155/2017/8146248.

13. Jin, F. L., Li, X., Park, S. J. (2015). Synthesis and application of epoxy resins: A review. Journal of Industrial and Engineering Chemistry, 29, 1-11. DOI 10.1016/j.jiec.2015.03.026.

14. Ramos, V. D., Da Costa, H. M., Soares, V. L., Nascimento, R. S. (2005). Modification of epoxy resin: A comparison of different types of elastomer. Polymer Testing, 24, 387-394.

15. Chruściel, J. J., Leśniak, E. (2015). Modification of epoxy resins with functional silanes, polysiloxanes, silsesquioxanes, silica and silicates. Progress in Polymer Science, 41, 67-121. DOI 10.1016/j.progpolymsci.2014.08.001.

16. Ratna, D. (2003). Modification of epoxy resins for improvement of adhesion: A critical review. Journal of Adhesion Science and Technology, 17(12), 1655-1668. DOI 10.1163/156856103322396721.

17. Kou, Y., Zhou, W., Li, B., Dong, L., Duan, Y. E. et al. (2018). Enhanced mechanical and dielectric properties of an epoxy resin modified with hydroxyl-terminated polybutadiene. Composites Part A: Applied Science and Manufacturing, 114, 97-106. DOI 10.1016/j.compositesa.2018.08.016. 
18. Mathew, V. S., Sinturel, C., George, S. C., Thomas, S. (2010). Epoxy resin/liquid natural rubber system: Secondary phase separation and its impact on mechanical properties. Journal of Materials Science, 45(7), 1769-1781. DOI 10.1007/s10853-009-4154-8.

19. Gojny, F. H., Wichmann, M. H. G., Köpke, U., Fiedler, B., Schulte, K. (2004). Carbon nanotube-reinforced epoxycomposites: Enhanced stiffness and fracture toughness at low nanotube content. Composites Science and Technology, 64(15), 2363-2371. DOI 10.1016/j.compscitech.2004.04.002.

20. Park, Y. T., Qian, Y., Chan, C., Suh, T., Nejhad, M. G. et al. (2015). Epoxy toughening with low graphene loading. Advanced Functional Materials, 25(4), 575-585. DOI 10.1002/adfm.201402553.

21. Ratna, D. (2001). Mechanical properties and morphology of epoxidized soyabean-oil-modified epoxy resin. Polymer International, 50(2), 179-184. DOI 10.1002/(ISSN)1097-0126.

22. Stroganov, V., Stoyanov, O., Stroganov, I., Kraus, E. (2018). Functional modification effect of epoxy oligomers on the structure and properties of epoxy hydroxyurethane polymers. Advances in Materials Science and Engineering, 2018, 1-16. DOI 10.1155/2018/6743037.

23. Deng, S., Djukic, L., Paton, R., Ye, L. (2015). Thermoplastic-epoxy interactions and their potential applications in joining composite structures-A review. Composites Part A: Applied Science and Manufacturing, 68, 121-132. DOI 10.1016/j.compositesa.2014.09.027.

24. Li, Y., Pan, D., Chen, S., Wang, Q., Pan, G. et al. (2013). In situ polymerization and mechanical, thermal properties of polyurethane/graphene oxide/epoxy nanocomposites. Materials \& Design, 47, 850-856. DOI 10.1016/j. matdes.2012.12.077.

25. Jia, Q. M., Zheng, M. S., Chen, H. X., Shen, R. J. (2006). Morphologies and properties of polyurethane/epoxy resin interpenetrating network nanocomposites modified with organoclay. Materials Letters, 60(9-10), 13061309. DOI 10.1016/j.matlet.2005.11.018.

26. Goertzen, W. K., Kessler, M. R. (2007). Dynamic mechanical analysis of carbon/epoxy composites for structural pipeline repair. Composites Part B: Engineering, 38(1), 1-9. DOI 10.1016/j.compositesb.2006.06.002.

27. Abdalla, M., Dean, D., Robinson, P., Nyairo, E. (2008). Cure behavior of epoxy/MWCNT nanocomposites: The effect of nanotube surface modification. Polymer, 49(15), 3310-3317. DOI 10.1016/j.polymer.2008.05.016.

28. Soares, B. G., Dahmouche, K., Lima, V. D., Silva, A. A., Caplan, S. P. C. et al. (2011). Characterization of nanostructured epoxy networks modified with isocyanate-terminated liquid polybutadiene. Journal of Colloid and Interface Science, 358(2), 338-346. DOI 10.1016/j.jcis.2011.03.030.

29. Tao, Q., Gan, W., Yu, Y., Wang, M., Tang, X. et al. (2004). Viscoelastic effects on the phase separation in thermoplastics modified cyanate ester resin. Polymer, 45(10), 3505-3510. DOI 10.1016/j.polymer.2004.03.043.

30. Feng, Y., He, C., Wen, Y., Zhou, X., Xie, X. et al. (2018). Multi-functional interface tailoring for enhancing thermal conductivity, flame retardancy and dynamic mechanical property of epoxy/ $\mathrm{Al}_{2} \mathrm{O}_{3}$ composites. Composites Science and Technology, 160, 42-49. DOI 10.1016/j.compscitech.2018.03.009.

31. Guadagno, L., Raimondo, M., Naddeo, C., Russo, G., Vittoria, V. et al. (2011). Healing efficiency and dynamic mechanical properties of self-healing epoxy systems. In Applied Mechanics and Materials, 62, 95-105. DOI 10.1088/0964-1726/23/4/045001.

32. Soares, B. G., Gonçalez, V., Galimberti, R., Sirqueira, A. S., Barcia, F. L. et al. (2008). Toughening of an epoxy resin with an isocyanate-terminated polyether. Journal of Applied Polymer Science, 108(1), 159-166. DOI 10.1002/(ISSN)1097-4628.

33. Shah, A. H., Li, X., Xu, X., Dayo, A. Q., Liu, W. et al. (2019). Evaluation of mechanical and thermal properties of modified epoxy resin by using acacia catechu particles. Materials Chemistry and Physics, 225, 239-246. DOI 10.1016/j.matchemphys.2018.12.063.

34. Liu, Y. L., Wei, W. L., Hsu, K. Y., Ho, W. H. (2004). Thermal stability of epoxy-silica hybrid materials by thermogravimetric analysis. Thermochimica Acta, 412(1-2), 139-147. DOI 10.1016/j.tca.2003.09.004.

35. Meure, S., Wu, D. Y., Furman, S. A. (2010). FTIR study of bonding between a thermoplastic healing agent and a mendable epoxy resin. Vibrational Spectroscopy, 52(1), 10-15. DOI 10.1016/j.vibspec.2009.09.005.

36. Liu, S., Wang, G., Wang, X. (2019). Application of infrared spectroscopy in chemical modification of epoxy resin. Information Recording Material, 20, 61-62. DOI 10.16009/j.cnki.cn13-1295/tq.2019.06.031. 